\title{
Keyhole Limpet Hemocyanin Antibody
}

National Cancer Institute

\section{Source}

National Cancer Institute. Keyhole Limpet Hemocyanin Antibody. NCI Thesaurus. Code C120495.

Any immunog lobulin that recognizes keyhole limpet hemocyanin protein. 